\title{
Constrictive Pericarditis with Atrial Septal Defect in Children
}

\author{
Kensuke Harada, M.D., Ichiro Seki, M.D., \\ and Masahiko OKuni, M.D., F.A.C.C.
}

\begin{abstract}
Summary
Two cases (1-year-old and 13-year-old) of constrictive pericarditis (CP) associated with atrial septal defect (ASD) are presented. The correct diagnosis was made preoperatively in both cases. Both patients underwent surgery (pericardiectomy and ASD closure). One patient died soon after the surgery because of low caridac output. The other patient was associated with protein-losing enteropathy and it improved dramatically after the operation. Cardiac catheterization is necessary for the diagnosis of this unusual combination. The cause of this unusual combination is obscure.
\end{abstract}

Additional Indexing Words :

Constrictive pericarditis Atrial septal defect Protein-losing enteropathy

\begin{abstract}
TRIAL septal defect is one of the most common congenital malformaA tions of the heart. Constrictive pericarditis is less common in childhood especially under the age of $10 . .^{1)}$ The association of CP with ASD is extremely rare and only 12 cases $^{2)-8)}$ have been reported. We recently studied 2 cases of CP associated with ASD in pediatric age group. Most of the patients reported previously are adult. These 2 cases of ours are the youngest patients with this unusual combination.
\end{abstract}

\section{Case Rerort}

Case 1.

The patient was well until 5 months old when he developed poor feeding, fever, and cyanosis. He was admitted to another hospital, where chest roentogenogram revealed totally opaque left lung field. Thoracocentesis revealed hemothorax. A week later he developed chylothorax and was treated with medium chain triglyceride (MCT). He, however, developed congestive heart failure and

From the Department of Pediatrics, Cardiology Division, Nihon University School of Medicine, Tokyo, Japan.

Address for reprints: K. Harada, M. D., Department of Pediatircs, Nihon University School of Medicine, 30 Kamimachi, Oyaguchi, Itabashi-ku, Tokyo 173, Japan.

Recived for publication November 25, 1977. 
was referred to Nihon University Hospital on Sept. 11, 1975. Physical examination revealed poorly nourished child and facial edema was noted. The pulse was regular, $152 / \mathrm{min}$, respiration, $66 / \mathrm{min}$ and blood pressure $110 / 62 \mathrm{mmHg}$ without paradoxical pulse. There was a grade $3 / 6$ harsh ejection type systolic murmur along left sternal border. A grade 2/6 diastolic rumble was heard at lower left sternal border. Second sound was narrowly split. A liver edge was felt $2 \mathrm{~cm}$ below the right costal margin. The electrocardiogram (Fig. 1) revealed normal sinus rhythm, right ventricular hypertrophy, diminished left ventricular forces and diffuse ST-T changes. Chest rentogenogram (Fig. 2) showed moderate cardio-

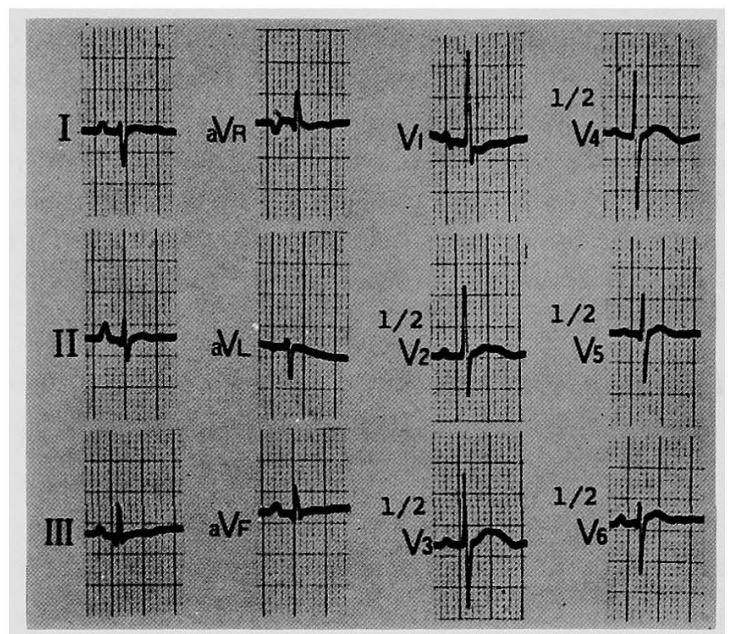

Fig. 1. Case 1. Electrocardiogram.

There are marked right axis deviation, right ventricular hypertrophy, mild low voltage in limb leads and ST-T changes in all limb and precordial leads.

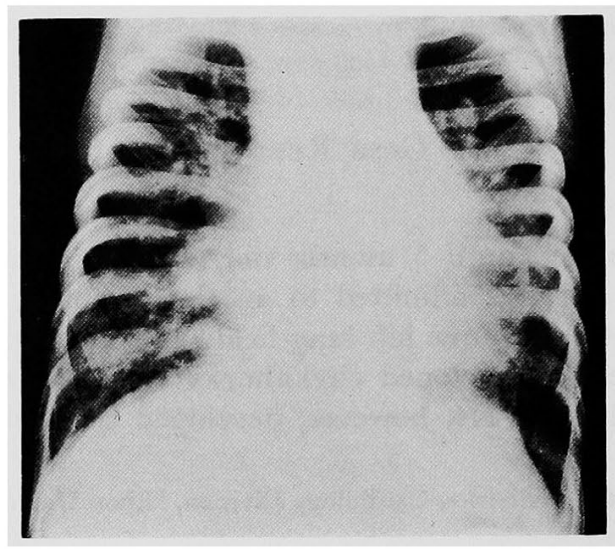

Fig. 2. Case 1. Chest renogenogram.

The heart size is moderately increased. There is a sign of increased hilar markings suggestive of left to right shunt. 
megaly, pulmonary congestion, and pleural adhesion. Sodium restriction, digitalis, and diuretics were instituted and congestive heart failure was improved. Cardiac catheterization on Sept. 26, 1975 (Table I) showed a left to right shunt at the atrial level, elevated right atrial pressure, mild pulmonary hypertension, and systolic gradient of $20 \mathrm{mmHg}$ across the pulmonary valve. This gradient was though to be due to a flow related pulmonary stenosis. Fluoroscopy revealed poor cardiac motion and presence of pericardial effusion was suspected. Pericardiocentesis was performed and $45 \mathrm{ml}$ of serosanguineous fluid was removed. A month later the patient was discharged.

On Jan. 23, 1976, he was readmitted because of severe congestive heart failure with left pleural effusion. The patient was treated with digitalis and diuretics and was discharged 2 weeks later. On Aug. 16, 1976 he was admitted again because of poor feeding and dehydration. Electrocardiogram showed atrial fibrillation. He was complicated with disseminated intravascular coagulation and was treated with heparin. Despite vigorous treatment for congestive heart failure, it didn't improve. Echocardiogram on Oct. 29, 1976 revealed no pericardial effusion but poor left ventricular contractility. He was thought to have $\mathrm{CP}$ and repeat cardiac catheterization was performed on Nov. 18, 1976. It revealed again a left to right shunt at atrial level. Right atrial mean pressure was markedly elevated and a diastolic right ventricular "dip" and plateau was noted. Pulmonary artery was not entered. On Nov. 30, 1976 the patient was transferred to the operating room. At thoracotomy, CP with thick adhesion over both ventricle was found. Pericardial resection was done, and then a $3 \times 3 \mathrm{~cm}$ secundum type ASD was closed. He, however, dropped into low cardiac output state and died soon after the operation. Autopsy was not performed.

Case 2.

A 13-year-old girl was referred to Nihon University Hospital on July 7, 1975

Table I. Cardiac Catheterization Data (Case 1)

\begin{tabular}{|c|c|c|}
\hline & $\begin{array}{c}\mathrm{O}_{2} \text { Saturations } \\
(\%)\end{array}$ & $\begin{array}{l}\text { Pressures } \\
(\mathrm{mmHg})\end{array}$ \\
\hline Superior vena cava & 72 & \\
\hline \multirow[t]{3}{*}{ Right atrium } & 81 & $a=12$ \\
\hline & & $v=12$ \\
\hline & & $m=9$ \\
\hline Right ventricle & 89 & $65 / 15$ \\
\hline Pulm. artery & 89 & $45 / 15 \quad m=30$ \\
\hline \multirow[t]{3}{*}{ Left atrium } & 93 & $a=15$ \\
\hline & & $\mathrm{v}=12$ \\
\hline & & $\mathrm{m}=10$ \\
\hline \multicolumn{3}{|l|}{ Flow $\left(\mathrm{L} / \mathrm{min} / \mathrm{M}^{2}\right)$} \\
\hline Pulmonary (Qp) & \multicolumn{2}{|c|}{9.5} \\
\hline Systemic (Qs) & \multicolumn{2}{|c|}{5.0} \\
\hline Pulmonary resistance (Unit) & \multicolumn{2}{|c|}{2.1} \\
\hline Qp/Qs & \multicolumn{2}{|c|}{1.9} \\
\hline
\end{tabular}


because of edema. A heart murmur was first noted at the age of 7 in another hospital, and clinical diagnosis of ventricular septal defect was made. She had been asymptomatic until 1 week prior to admission when she first noticed edema on legs. Physical examination revealed a well nourished and developed girl. The pulse was reqular, $82 / \mathrm{min}$, respiration, $22 / \mathrm{min}$ and blood pressure, $118 / 62 \mathrm{mmHg}$ without paradoxical pulse.

Jugular vein was distended. There was a grade $3 / 6$ harsh ejection type systolic murmur, best heart at upper left sternal border, followed by a fixed wide split second sound. No diastolic rumble was heard. Faint third sound was present at the apex. No thrill was felt. A non-tender liver edge was felt $4 \mathrm{~cm}$ below the

A)

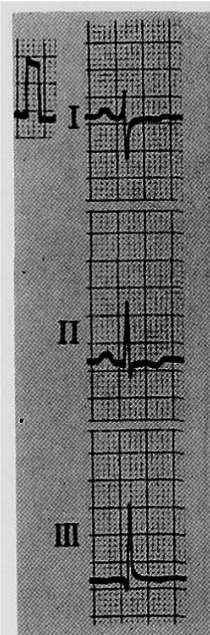

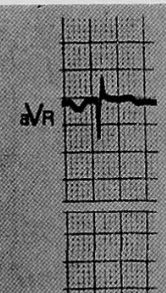

d.
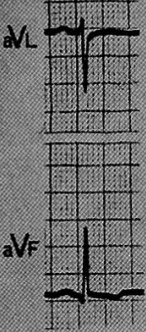
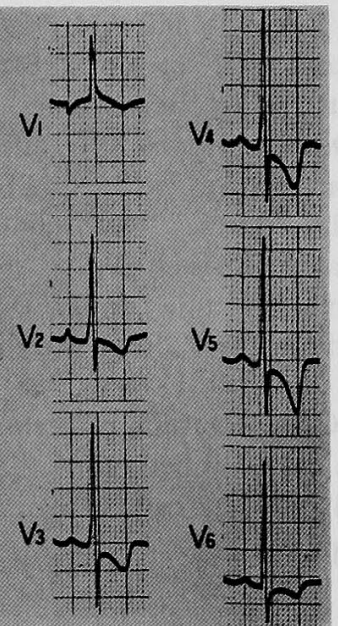

B)

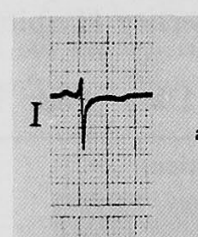

W/R

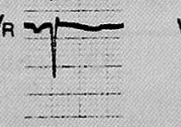

$v_{1}$
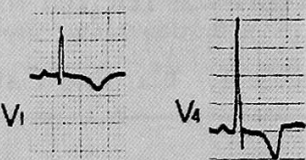

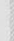

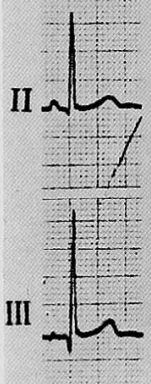

aV
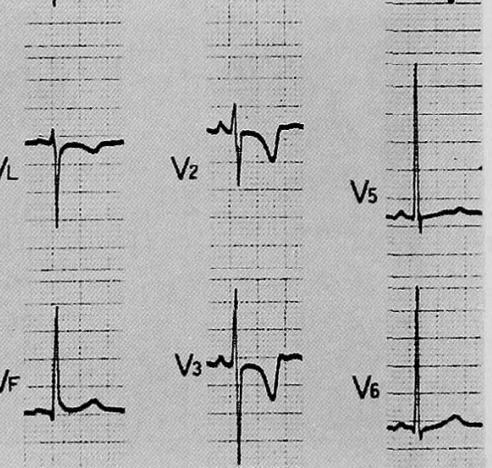

Fig. 3. Case 2. Electrocardiogram.

(A) Preoperative: Note $\mathrm{T}$ wave inversion in II, III, $\mathrm{aVF}$, and $\mathrm{V}_{1} \sim \mathrm{V}_{6}$, and right ventricular hypertrophy.

(B) Eight months postoperative: Note positive $\mathrm{T}$ wave in II, III, aVF, and $V_{5} \sim V_{6}$. Right ventticular hypertrophy still remained. 
right costal margin. The presence of ascites was suspected, and abdominal mass was felt at the lower abdomen.

The electrocardiogram (Fig. 3A) revealed normal sinus rhythm, $T$ wave in-

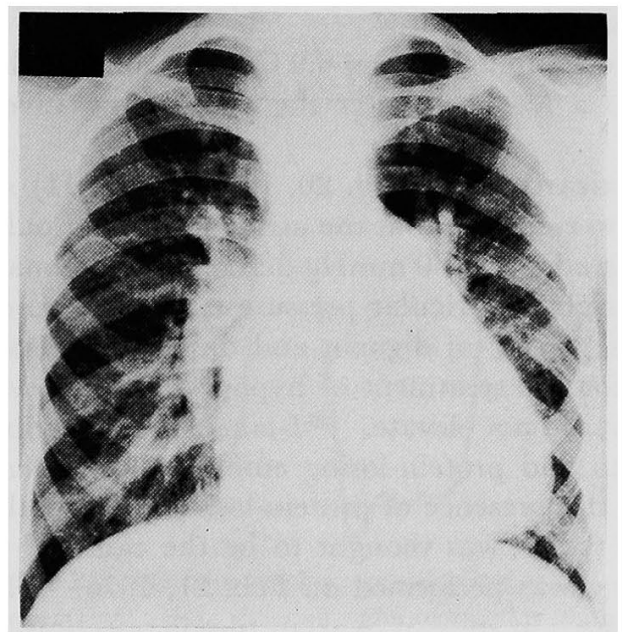

Fig. 4. Case 2. Chest rentogenogram.

The heart is moderately enlarged. The pulmonary vascular marking is increased. The pulmonary artery segment is prominent.

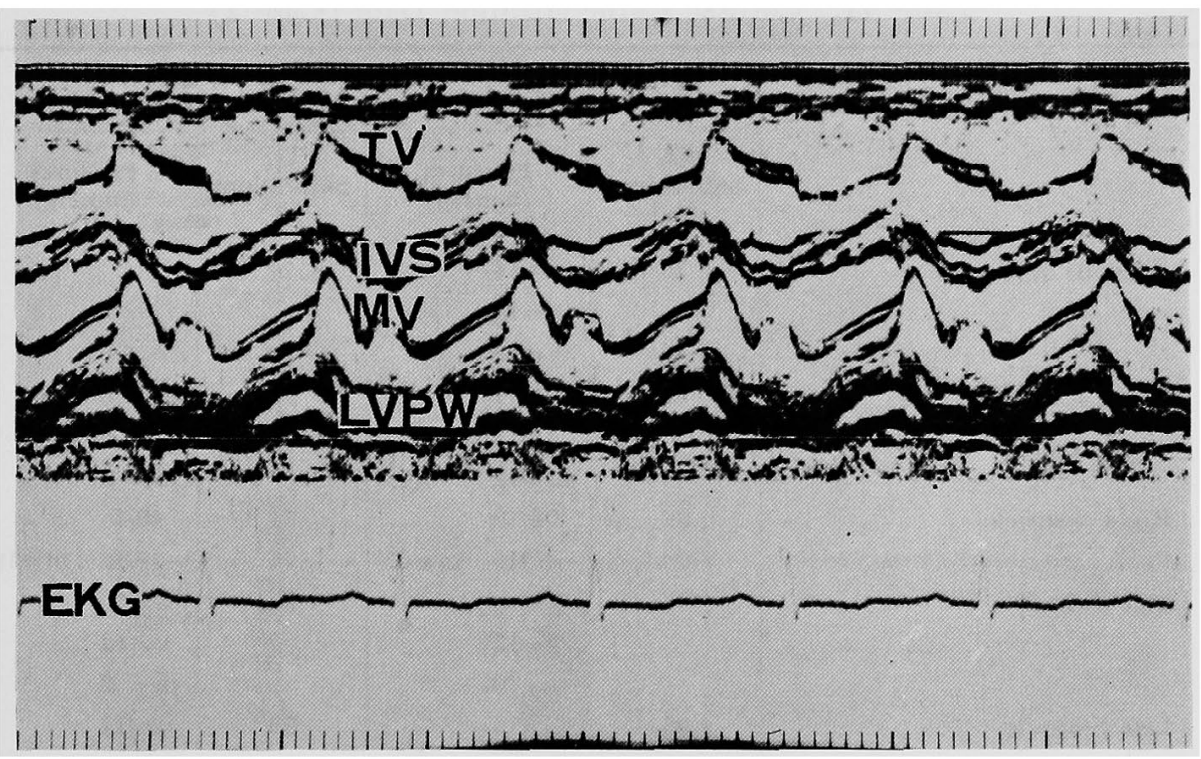

Fig. 5. Case 2. Echocardiogram (preoperative).

Note increased right ventricular dimension and paradoxical interventricular septal motion. There is a sign of minimal pericardial effusion. $\mathrm{RV}=$ right ventricle; IVS = interventricular septum; $\mathrm{TV}=$ tricuspid valve; $\mathrm{MV}=$ mitral valve;

$\mathrm{LVPW}=$ left ventricular posterior wall; EKG=electrocardiogram. 
version in leads II, III, aVF and chest leads. No low voltage was present.

Chest rentogenogram (Fig. 4) showed cardiomegaly and increased pulmonary flow. There was no calcification. Echocardiogram (Fig. 5) revealed increased right ventricular dimention, paradoxical motion of the interventricular septum and minimal pericardial effusion.

Serum protein on admission was $6.0 \mathrm{Gm} / 100 \mathrm{ml}$. It, however, decreased to below $5.0 \mathrm{Gm} / 100 \mathrm{ml}$ a few days after the admission. Liver function tests were normal.

Cardiac catheterizartion on Aug. 20, 1975 (Table II) showed elevated right atrial pressure, a left to right shunt at the atrial level, mild pulmonary artery hypertension, and systolic gradient of $30 \mathrm{mmHg}$ across the pulmonary valve. A diastolic "dip" and plateau right ventricular pressure curve was noted (Fig. 6A).

The patient was placed on digoxin and diuretics. Plasma and albumin was given intravenously for the treatment of hypoproteinemia every day. The serum protein livel, however, did not elevate. ${ }^{131}$ I-labeled polyvinylpyrrolidone (PVP) was given intravenously to find protein-losing enteropathy. Fecal output of ${ }^{131}$ I-PVP was $25 \%$, indicating the presence of protein-losing enteropathy.

The abdominal tumor was thought to be the cause of protein-losing enteropathy and laparotomy was performed on Feb. 21, 1976. The tumor was benign ovarian cystic teratoma. In spite of ovarian tumor resection, ascites reaccumulated and serum protein remained low. The patient was thought to have CP and was referred to cardiac surgery. On April 4, 1976 operation was performed. The peri-

Table II. Cardiac Catheterization Data (Case 2)

\begin{tabular}{|c|c|c|c|c|}
\hline & \multicolumn{2}{|c|}{$\begin{array}{c}\text { Preoperative } \\
(8 / 2 / 75)\end{array}$} & \multicolumn{2}{|c|}{$\begin{array}{c}\text { Postoperative } \\
(12 / 3 / 76)\end{array}$} \\
\hline & $\begin{array}{c}\mathrm{O}_{2} \\
\text { Saturations } \\
(\%)\end{array}$ & $\begin{array}{l}\text { Pressures } \\
(\mathrm{mmHg})\end{array}$ & $\begin{array}{c}\mathrm{O}_{2} \\
\text { Saturations } \\
(\%)\end{array}$ & $\begin{array}{l}\text { Pressures } \\
(\mathrm{mmHg})\end{array}$ \\
\hline Superior vena cava & 75 & $\begin{array}{r}a=14 \\
v=10 \\
m=12\end{array}$ & 72 & \\
\hline Right atrium & 87 & $\begin{array}{r}a=14 \\
v=8 \\
m=12\end{array}$ & 72 & $\begin{aligned} \mathrm{a} & =5 \\
\mathrm{v} & =6 \\
\mathrm{~m} & =3\end{aligned}$ \\
\hline Right ventricle & 86 & $70 / 10$ & 74 & $40 / 4$ \\
\hline Pulm. artery & 89 & $40 / 15 \quad m=25$ & 74 & $32 / 12 \mathrm{~m}=19$ \\
\hline Left atrium & 96 & $\begin{array}{r}a=8 \\
v=12 \\
m=10\end{array}$ & 95 & $\begin{array}{l}a=10 \\
\mathrm{v}=12 \\
\mathrm{~m}=6\end{array}$ \\
\hline Left ventricle & 96 & $125 / 15$ & 95 & $126 / 12$ \\
\hline \multicolumn{5}{|l|}{ Flow $\left(\mathrm{L} / \mathrm{min} / \mathrm{m}^{2}\right)$} \\
\hline Pulmonary (Qp) & & 10.5 & & 3.6 \\
\hline Systemic (Qs) & & 3.5 & & 3.5 \\
\hline Pulmonary resistance (Unit) & & 1.4 & & 3.6 \\
\hline$Q p / Q s$ & & 3.0 & & 1.0 \\
\hline
\end{tabular}


A)

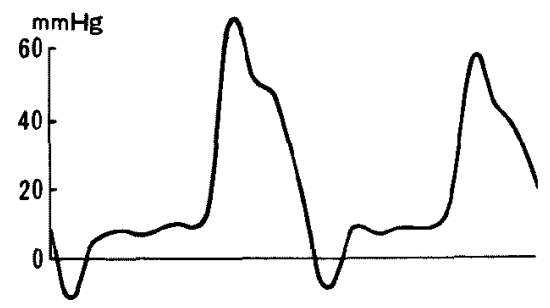

B)

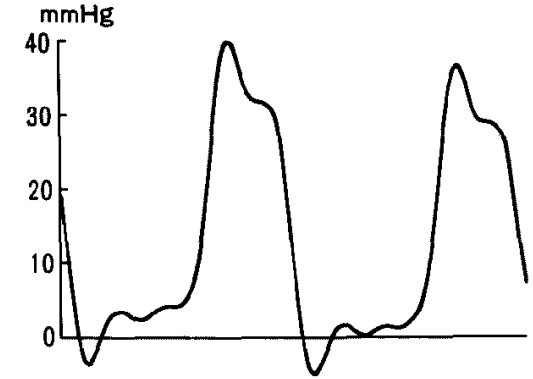

Fig. 6. Case 2. Right ventricular pressure curve.

(A) Preoperative: Note elevated right ventricular pressure and a diastolic "dip" and plateau curve.

(B) Eight months postoperative: Right ventricular pressure decreased. A "dip" and plateau curve still remained.

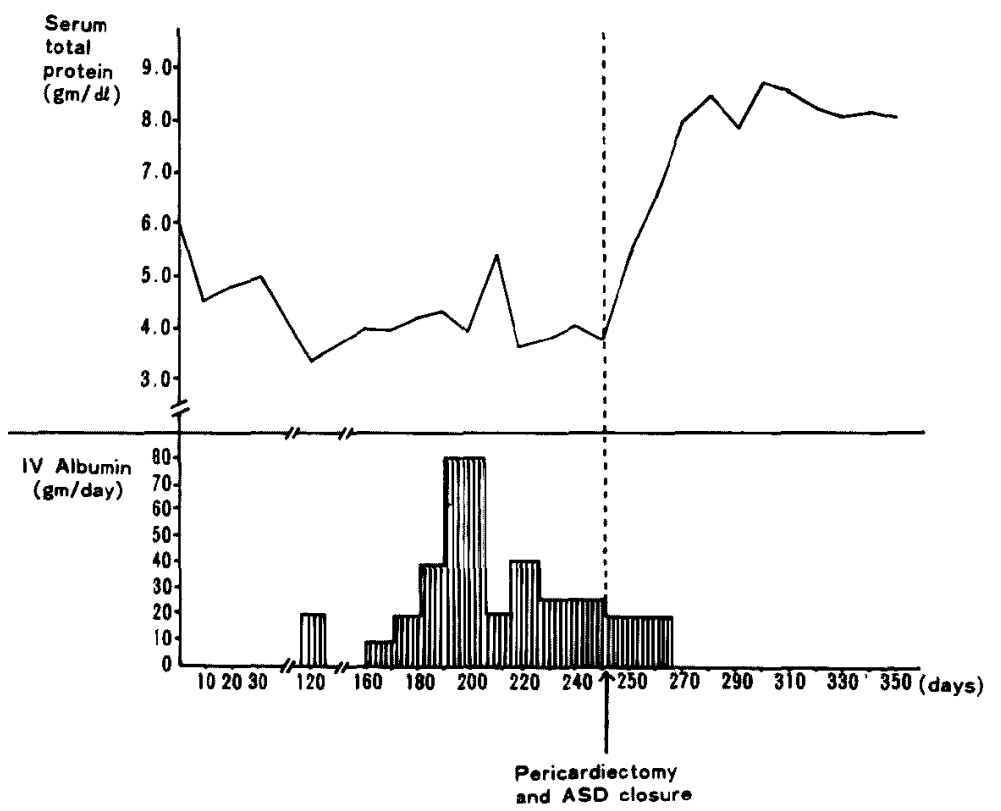

Fig. 7. Change of serum total protein. 
cardium was found to be markedly thickened ( $3 \mathrm{~mm}$ thick). Pericardiectomy was successfully done, and a $3 \times 4 \mathrm{~cm}$ secundum type atrial septal defect was closed with the aid of extracorporal circulation. Postoperatively the patient was complicated with transient atrial flutter, but signs of congestive heart failure reduced gradually with digitails and diuretic therapy. Intraveous albumin administration was continued after the operation. Three weeks after the operation, serum protein level rose above $7.0 \mathrm{mg} / 100 \mathrm{ml}$ and intravenous albumin was discontinued (Fig. 7). Serum protein level remained above $7.0 \mathrm{Gm} / 100 \mathrm{ml}$ and the signs of ascites and congestive heart failure disappeared. She was discharged on Aug. 20, 1976.

Eight months after the operation repeat cardiac catheterization was carried out on December 3, 1976 (Table II). The catheter was entered through the atrial septum to the left atrium. No significant shunt at the atrial level, however, was demonstrated. Right atrial and right ventricular end-diastolic pressure were normal, but a right ventricular diastolic " dip " and plateau curve was still remained (Fig. 6B).

\section{Discussion}

Constrictive pericarditis is far less common in children than adult, and is particularly rare in young children. In our pediatric department, 3 out

Table III. Summary

\begin{tabular}{|c|c|c|c|c|c|c|c|}
\hline No. & Author & Year & Age & Sex & $\begin{array}{l}\text { Type } \\
\text { of } \\
\text { ASD }\end{array}$ & $\begin{array}{l}\text { Systolic } \\
\text { murmur }\end{array}$ & $\begin{array}{l}\text { Diastolic } \\
\text { rumble }\end{array}$ \\
\hline 1 & Gignoux* & 1910 & $?$ & $\mathbf{M}$ & $2^{\circ}$ & $?$ & $?$ \\
\hline 2 & Quirno and Battro* & 1936 & 22 & $\mathbf{M}$ & $2^{\circ}$ & $?$ & $?$ \\
\hline 3 & \multirow{2}{*}{ Semler and coworkers ${ }^{2)}$} & 1960 & 33 & M & $2^{\circ}$ & + & - \\
\hline 4 & & 1960 & 17 & $\mathbf{M}$ & $2^{\circ}$ & + & - \\
\hline 5 & Mihailescu* & 1962 & 46 & $\mathrm{~F}$ & $2^{\circ}$ & $?$ & $?$ \\
\hline 6 & Yurchak and coworkers ${ }^{3\}}$ & 1965 & 68 & $\mathbf{M}$ & $2^{\circ}$ & + & + \\
\hline 7 & Yahini and coworkers ${ }^{4}$ & 1966 & 51 & $\mathbf{M}$ & $2^{\circ}$ & + & - \\
\hline 8 & Just and Mattingly ${ }^{5}$ & 1967 & 27 & $\mathbf{M}$ & $2^{\circ}$ & $?$ & $?$ \\
\hline 9 & \multirow{2}{*}{ Albers and coworkers ${ }^{6)}$} & 1969 & 40 & $\mathbf{M}$ & $2^{\circ}$ & + & - \\
\hline 10 & & 1969 & 14 & $\mathbf{M}$ & $2^{\circ}$ & + & - \\
\hline 11 & Kumar and coworkers ${ }^{n}$ & 1971 & 65 & $\mathbf{M}$ & $2^{\circ}$ & + & + \\
\hline 12 & Kotoda and coworkers ${ }^{8)}$ & 1972 & 28 & $\mathbf{M}$ & $2^{\circ}$ & - & - \\
\hline 13 & \multirow{2}{*}{ Harada and coworkers } & & 1 & $\mathbf{M}$ & $2^{\circ}$ & + & + \\
\hline 14 & & & 13 & $\mathrm{~F}$ & $2^{\circ}$ & + & + \\
\hline
\end{tabular}

$*=$ Quoted from Just's paper ${ }^{5)} ; 2^{\circ}=$ Secundum type atrial septal defect $; \mathrm{FS}=$ fixed split $; \mathrm{NS}=$ 
of 25 cases of pericarditis developed constriction. Two of them are the reported cases in this paper. One is tuberculous CP. The incidence of CP is $12 \%$ of all cases of pericarditis. Reviews on pericarditis in children have shown an incidence of constriction ranging from 0.7 to $13 \%{ }^{.9,10)}$

The association of pericardial disease and congenital heart malformation has been rarely reported in the past. ${ }^{2,11)}$ The combination of CP and ASD is quite rare and to the best of our knowledge, only 12 cases have been reported (Table III). Most of them are adults. A 14-year-old patient was reported by Albers et al.6) This is the only patient in pediatric age group. Case 1 in this report is the youngest on record.

Constrictive pericarditis is predominantly a disease of male. In reviewing the sex incidence of $\mathrm{CP}$ with $\mathrm{ASD}$, only one female case has been repoted. Our patient (Gase 2) is the second female case on record.

Although CP is rare in assoceation with congenital malformations of the heart, ASD has the highest tendency to associate with pericardial disease. Just and Mattingly ${ }^{5}$ reviewed 67 cases of pericardial disease associated with ASD. They described that $12 \%$ of autopsy cases of ASD had some degree of of Cases Reviewed

\begin{tabular}{|c|c|c|c|c|c|c|c|c|c|}
\hline $\begin{array}{l}\text { Second } \\
\text { sound }\end{array}$ & $\begin{array}{l}\text { Para- } \\
\text { doxical } \\
\text { pulse }\end{array}$ & Ascites & $\begin{array}{l}\text { Hepato- } \\
\text { megaly }\end{array}$ & Edema & $\begin{array}{l}\text { Cardio- } \\
\text { megaly }\end{array}$ & $\begin{array}{l}\text { Calcfi- } \\
\text { cation }\end{array}$ & $\begin{array}{c}\text { Friction } \\
\text { rub }\end{array}$ & $\begin{array}{c}\text { Opera- } \\
\text { tion }\end{array}$ & Outcome \\
\hline$?$ & $?$ & $?$ & $?$ & $?$ & $?$ & $?$ & $?$ & $?$ & $?$ \\
\hline$?$ & $?$ & $?$ & $?$ & $?$ & $?$ & $?$ & $?$ & $?$ & $?$ \\
\hline NS & $?$ & $?$ & $?$ & $?$ & + & + & $?$ & + & $\mathrm{S}$ \\
\hline NS & $?$ & + & + & $?$ & + & $?$ & $?$ & + & $S$ \\
\hline$?$ & $?$ & $?$ & $?$ & $?$ & $?$ & $?$ & $?$ & $?$ & $?$ \\
\hline FS & $?$ & - & + & $?$ & + & + & + & + & $\mathrm{s}$ \\
\hline $\mathrm{FS}$ & - & - & + & - & + & - & - & + & $\mathrm{D}$ \\
\hline$?$ & $?$ & $?$ & $?$ & $?$ & $?$ & $?$ & $?$ & + & $\mathrm{S}$ \\
\hline NS & - & $?$ & + & + & + & + & - & + & $\mathrm{S}$ \\
\hline $\mathrm{FS}$ & - & + & + & + & + & $?$ & + & + & $\mathrm{S}$ \\
\hline NS & $?$ & + & + & + & + & + & $?$ & - & $\mathrm{D}$ \\
\hline FS & - & + & + & + & + & - & - & + & $\mathrm{S}$ \\
\hline NS & - & + & + & + & + & - & - & + & $\mathrm{D}$ \\
\hline FS & - & + & + & + & + & - & - & + & $\mathrm{S}$ \\
\hline
\end{tabular}

normally split; $\mathrm{D}=$ died ; $\mathrm{S}=$ survived 
pericardial disease. To our knowledge, there is no such a tendency in other congenital malformations of the heart. In reviewing previously reported cases and our cases, only secundum type ASD associates with CP, although pericardial effusion is demonstrated in primum type as well as secundum type ASD. Why does pericardial effusion occur in association with ASD? One of the explanations is that elevation of right atrial pressure caused by a left to right shunt at the atrial level compress the coronary sinus, followed by pericardial effusion. Experimental work suggests that compression of the coronary sinus results in accumulation of pericardial effusion. ${ }^{12}$ The true explanation, however, remains obscure.

It is well known that CP accompanies hypoproteinemia. ${ }^{13}$ ) All the previously reported cases with $\mathrm{CP}$ and ASD are not associated with hypoproteinemia. Our patient (Case 2) is the first case complicated with CP, ASD, and hypoproteinemia. Usually CP produces ascites and facial edema and a clinical picture resembles nephrotic syndrome. It is called " pseudonephrosis". Protein-losing enteropathy is the major cause of hypoproteinemia in CP. Hypoproteinemia may also be the result of impaired liver function followed by impaired protein production, loss of protein to the ascites or increased plasma volume by dilution. ${ }^{15)}$ In our patient, the abnormal permeability of the gut to serum protein was studied by the intravenous administration of ${ }^{131}$ I-PVP. ${ }^{14)}$ The loss of ${ }^{131}$ I-PVP to the feces was markedly elevated. The liver function tests were normal. Therefore we concluded that the cause of hypoproteinemia of this patient was loss of protein to the feces. Since this patient had ovarian tumor, it misled the cause of protein-losing enteropathy.

The relationship between protein-losing enteropathy and congestive heart failure has been discussed. ${ }^{15)}$ Davidson et al studied 3 cases of chronic constrictive pericarditis and ASD with congestive heart failure utilizing intravenous ${ }^{131} \mathrm{I}-\mathrm{PVP}$ and ${ }^{131} \mathrm{I}$-albumin. The permeability of the gut to ${ }^{131} \mathrm{I}$ PVP was higher than normal. ${ }^{131} \mathrm{I}$-albumin turnover studies indicated that hypoalbuminemia was related to subnormal body albumin content and this was the result of an increased rate of albumin catabolism, and not of a failure of albumin synthesis. Why does congestive heart failure predispose gastrointestinal system to loss of plasma protein? A hypothesis is that the elevated venous pressure leads to lymphatic congestion of the intestine as a result of impaired venous return. ${ }^{16}$ ) This fact can give rise to loss of protein through the intestinal wall and result in protein-losing enteropathy. In other cardiac diseases, however, it is extremely rare to cause protein-losing enteropathy even being accompanied by severe congestive heart failure. Constrictive pericarditis might have some specific reason to predispose gastrointestinal system to 
loss of plasma protein.

The clinical diagnosis of ASD is relatively easily suspected. Physical examination and echocardiogram play a major role for the diagnosis of ASD.

Echocardiographic features of ASD was well defined. ${ }^{17-20}$ Paradoxical interventricular septal motion and increased right ventricular dimension are the echocardiographic findings of right ventricular volume overloading. Pool et $\mathrm{a}^{21)}$ studied the septal motion of CP and found that the interventricular septum moves paradoxically. They concluded that the septal motion of CP was indistinguishable from paradoxical motion associated with right ventricullar volume overloading. Gibson et $\mathrm{al}^{22)}$ also mentioned abnormal septal motion in CP. This abnormal septal motion is also observed in left bundle branch block ${ }^{23), 24)}$ and septal damage. ${ }^{25,26)}$ Since left bundle branch block is rare in children, paradoxical septal motion in echocardiogram suggests right ventricular volume overloading and/or CP. In association with CP and ASD, echocardiogram is not diagnostic of either ASD or CP. Since it is very rare to develop congestive heart failure in children with ASD, echocardiographic paradoxical septal motion with the signs of severe congestive heart failure suggests the possibility of CP.

Although the signs of ascites, venous distention, hepatomegaly and peripheral edema were noted, paradoxical pulse was not observed in either patient. Paradoxical pulse was almost invariably present in the majority of cases of CP in Wood's series. ${ }^{27)}$ It was not observed in Albers ${ }^{6)}$ and Yahini's cases $^{4)}$ as well as our cases. Paradoxical pulse depends on respiratory variations of systemic venous return to the right side of the heart. If right ventricular output was kept constant, paradoxical pulse could not be produced despite an increase in pericardial pressure. In presence of ASD, the blood volume in the right side of the heart remains constant during inspiration and expiration. This is probably the reason why paradoxical pulse is absent in patients with CP and ASD.

Gardiac catheterization is the crucial procedure for the diagnosis of CP. Elevated venous pressure and $M$ shaped (steep $\mathrm{X}$ and $\mathrm{Y}$ descents) atrial pressure curve is characteristic." A diastolic "dip" and plateau curve in right ventricle is diagnostic. Our patient's postoperative cardiac catheterization, repeated 8 months after the operation, revealed a right ventricular "dip" and plateau curve, although she was clinically asymptomatic. Myocardial atrophy has been demonstrated in patients with CP. ${ }^{28}$ ) Probably this is the factor considered to be responsible for persistent right ventricular " dip " and plateau curve.

Constriction in children is not necessarily a chronic disease as in adult. In our patient (Case 1), constriction developed at most within 6 months after 
effusive pericarditis. Rapidly developed $\mathrm{CP}$ has been reported by other authors. Strauss et al $^{10)}$ reported a case in which $\mathrm{CP}$ developed only within 8 weeks.

The similarities of CP and cardiomyopathy has been emphasized. ${ }^{6,27), 29)}$ In cardiomyopathy, the left atrial and/or pulmonary capillary wedge pressure has been found to be higher than right atrial pressure. In CP, both atrial pressures are elevated to an equal level. In the presence of ASD, both atrial pressures tend to be equalized. This fact makes this differentiation more difficult. Constrictive pericarditis is a correctable disease. Cardiomyopathy, however, is not a correctable disease. Therefore the differential diagnosis of these diseases is of great importance.

\section{REFERENCES}

1. Nadas AS, Fyler DC: Pediatric Cardiology. Philadelphia WB Saunders, p. 258, 1972

2. Samler HJ, Brandenburg RO, Kirklin JW: Pericardial disease complicating congenital heart leasions. Ann Int Med 53: 494, 1960

3. Yurchak P, Levine SA, Gorlin R: Constrictive pericarditis complicating disseminated lupus erythematosus. Circulation 31: 113, 1965

4. Yahini JH, Goor D, Kraus Y, Pauzner YM, Neufeld HN: Atrial septal defect and constrictive pericarditis. Am J Cardiol 17: 718, 1966.

5. Just H, Mattingly TW: Interatrial septal defect and pericardial disease. Am Heart J 76: 157,1968

6. Albers WH, Hugenholtz PG, Nadas AS: Constrictive pericarditis and atrial septal defect, secundum type. Am J Cardiol 23: 850, 1969

7. Kumar S, Szatkowski J, Thomas W: Atrial septal defect complicated by constrictive pericarditis. Chest 60: 101, 1971

8. Kotoda K, Mitsui T, Yoshitake A, Saegusa M: Atrial septal defect and constrictive pericarditis. Kyobugeka 25: 427, 1972 (in Japanese)

9. Simcha A, Tylor JFN: Constrictive pericarditis in childhood. Arch Dis Child 46: 515, 1971

10. Strauss AW, Santa-Maria S, Goldring D: Constrictive pericarditis in children. Am J Child 129: 822, 1975

11. Sammers JB, Stanley AL, Stringer CJ: Unusual case report. Coarctation of the aorta, constrictive pericarditis and pleuritis and primary carcinoma of the liver occuring in one person. J Indian MA 47: 1294, 1954

12. Moenckeberg JG, Henke F, Lubarsch O: Handbuch der speziellen Anatomie und Histologie. Berlin 2: 556, 1924

13. Watson H: Pediatric Cardiology. Mosby Co, Saint Louis, p. 722, 1968

14. Gordon RS: Exudative enteropathy. Abnormal permeability of the gastrointestinal tract demonstrable with labelled polyvinylpyrrolidone. Lancet $1: 325,1959$

15. Davidson JD, Waldmann TA, Goodmann DS, Gordon RS: Proteinlosing gastrocnteropathy in congestive heart failure. Lancet 1: 899, 1961

16. Peterson VP, Hastrup J: Protein-losing enteropathy in constrictive pericarditis. Acta Med Scand 173: 401, 1963

17. Popp PI, Wolfe SB, Hirata T, Feigenbaum $\mathbf{H}$ : Estimation of right and left ventricular size by ultrasound. A study of the echoes from the interventricular septum. Am J Cardiol 24: 523,1969 
18. Diamond MA, Dillon JC, Haine CL, Chang S, Feigenbaum H: Echocardiographic features of atrial septal defect. Circulation 43: 129, 1971

19. Tajik AJ, Gau GI, Ritter DC, Shattenberg TT: Echocardiographic pattern of right ventricular diastolic volume overload in children. Circulation 46: 36, 1972

20. Meyer RA, Schwarz DC, Benzing C, Kaplan S: Ventricular septum in right ventricular volume overload. Am J Cardiol 30: 349, 1972

21. Pool PE, Seagren SC, Abbasi AS, Charzui YC, Kraus R: Echocardiographic manifestation of constrictive pericarditis. Chest $65: 684,1975$

22. Gibson TC, Grossman W, McLaurin LP, Moos S, Craige E: An echocardiographic study of the interventricular septum in constrictive pericarditis. Brit Heart J 38: 738, 1976

23. Abassi AS, Eber LM, MacAlpin RN et al: Paradoxical motion of the interventricular septum in Left bundle branch block. Girculation 49: 423, 1974

24. Dillon JC, Chang S, Feigenbaum H: Echocardiographic manifestations of left bundle branch block. J Clin Ultra sound 1: 245, 1973 (abstract)

25. Brawn OR, Popp RL, Harrison DC: Abnormal interventricular septal motion in patients with significant disease of the left anterior descending coronary artery or other conditions of septal failure. Am J Cardiol 31: 123, 1973 (abstract)

26. Miller HC, libson DG, Stephens JD: Role of echocardiography and phonocardiography in diagnosis of mitral paraprosthet ic regurgitation with Starr-Edward prosthesis. Brit Heart J. 35: 1217, 1973

27. Wood P: Chronic constrictive pericarditis. Am J Cardiol 7: 48, 1961

28. Dines DE, Edwards JE, Burochell HB: Myocardial atrophy in constrictive pericarditis. Proc Mayo Clin 33: 93, 1958

29. Burwell SC, Robin ED: Diagnosis of diffuse myocardial fibrosis. Circulation 20: 606, 1959 